\title{
Physicochemical Characterization of Polysaccharides with Macrophage Immunomodulatory Activities Isolated from Red Ginseng (Panax ginseng C. A. Meyer)
}

\author{
Liang Zheng, Mengyue Wang, Ying Peng, and Xiaobo Li \\ School of Pharmacy, Shanghai Jiao Tong University, Shanghai 200240, China \\ Correspondence should be addressed to Xiaobo Li; xbli@sjtu.edu.cn
}

Received 12 June 2017; Accepted 25 July 2017; Published 23 August 2017

Academic Editor: Pasquale Longo

Copyright (c) 2017 Liang Zheng et al. This is an open access article distributed under the Creative Commons Attribution License, which permits unrestricted use, distribution, and reproduction in any medium, provided the original work is properly cited.

In this study, four polysaccharide fractions designated as RGP1, RGP2, RGP3, and RGP4 were isolated from red ginseng by DEAE52 cellulose chromatography, and their macrophage immunomodulatory activities were investigated. The results revealed that the proliferation, NO production, and neutral red phagocytosis of RAW 264.7 macrophage cells in groups treated with RGP1 and RGP2 in vitro were increased significantly compared to RGP3 and RGP4. In addition, the level of TNF- $\alpha$ in RAW 264.7 cells was significantly increased in RGP1 and RGP2 groups. All the results consistently indicated that polysaccharide fractions RGP1 and RGP2 had strong macrophage immunomodulatory activities. Furthermore, RGP1 and RGP2 were purified by Sephadex G-100 column and RGP2 was further fractionated into a homogeneous fraction RGP2-1, with the molecular weight of $2.16 \times$ $10^{4} \mathrm{Da}$. The analysis of monosaccharide composition revealed that RGP1 was composed of arabinose, glucose, and galactose with a relative molecular ratio of $0.02: 0.88: 0.10$. RGP2-1 was composed of rhamnose, arabinose, glucose, and galactose with a relative molecular ratio of $0.02: 0.10: 0.77: 0.11$. These results provided evidences that the neutral polysaccharide fractions RGP1 and RGP2 possessed significant immunomodulatory activity and could be explored as a promising natural immunomodulating agent applied in functional foods or medicines.

\section{Introduction}

Ginseng, the root of Panax ginseng C. A. Meyer (Araliaceae), has occupied an important place among the tonic remedies of oriental medicine for several thousand years with mysterious powers in Far East Asian. Ginseng contains various active components such as ginsenosides, polysaccharides, essential oils, fatty acids, and phenolic compounds $[1,2]$. White ginseng and red ginseng are two common types of ginseng in the herbal supplement market according to the processing methods [3]. White ginseng is produced by peeling and air-drying fresh ginseng, and red ginseng is made by repeated process of steaming and then air-drying fresh ginseng without peeling $[3,4]$. Red ginseng has been shown to possess higher biological effects and stability compared with fresh ginseng and white ginseng, and its chemical profiles are quite different from nonsteamed ginseng, because of numerous chemical changes which occur during the steaming process $[5,6]$. The processed red ginseng contains several distinct ginsenosides such as Rg3, Rk1, Rk3, and Rg5, which are absent from nonsteamed ginseng [7]. A great deal of study reported that these unique compounds have potent activities, such as anticancer and anti-inflammatory activities [8-10]. The steaming process also leads to a significant increase in reducing sugar, acidic polysaccharide, and phenolic compounds content [7]. Compared with the widespread research on ginsenosides of red ginseng, studies of the structure and bioactivity of polysaccharide fractions from red ginseng are limited, which restricts the application of these polysaccharides.

Nonetheless, studies done by several researchers shown that red ginseng acidic polysaccharide (RGAP) possesses desirable immunomodulatory activity [11]. RGAP was reported to have B cell specific mitogenic activity, increase the NK cell activity, induce a proliferation of spleen cells, and stimulate nitric oxide production in murine peritoneal macrophages 
in vivo $[12,13]$. In addition, RGAP was found to activate macrophage function through activation of transcription factors such as NF- $\kappa \mathrm{B}$ and AP-1 and their upstream signaling enzymes such as ERK and JNK [14]. As far as we know, the reported RGAP was a crude fraction containing $56.9 \%$ acidic sugars and $28.3 \%$ neutral sugars and its structure-activity relationships were still unclear [15]. Moreover, there was no systematic report about the extraction, isolation, purification, and structure characteristics of red ginseng polysaccharides.

In our study, the crude polysaccharides from red ginseng were further fractionated by DEAE-52 cellulose chromatography to evaluate the immunomodulatory activities of these fractions. Furthermore, the polysaccharide fractions with strong immunomodulatory activity were further purified by Sephadex G-100 column chromatography and their physicochemical properties were identified.

\section{Materials and Methods}

2.1. Materials. Red ginseng (Panax ginseng C. A. Meyer) was kindly supplied by Yunnan Dali Pharmaceutical Co., Ltd., China. Its botanical origins were identified by the corresponding author, and voucher specimens were deposited at the School of Pharmacy, Shanghai Jiao Tong University. DEAE-52 was bought from Whatman (Maidstone, Britain) and Sephadex G-100 was purchased from Amersham (Uppsala, Sweden); standard sugars and T-series Dextran, 3(4,5-dimethylthiazol-2-yl)-2,5-diphenyltetrazolium bromide (MTT), lipopolysaccharide (LPS), and neutral red were purchased from Sigma-Aldrich (St. Louis, USA); DMEM cell culture medium was purchased from HyClone (South Logan, USA); fetal bovine serum and penicillin/streptomycin were obtained from GIBCO (Grand Island, USA); Bradford Protein Quantification Kit, assay kit for nitric oxide, and the TNF- $\alpha$ mouse ELISA kit were obtained from Nanjing Jiancheng Bioengineering Institute (Nanjing, China). All other reagents in this research were of analytical grade or purer.

2.2. Extraction. Red ginseng powder ( $200 \mathrm{~g})$ was extracted thrice with $2000 \mathrm{~mL} 70 \%$ ethanol for $3 \mathrm{~h}$ ( $1 \mathrm{~h}$ each time) to remove ethanol-soluble substances. The residual powder was extracted twice with 10 -fold volume of distilled water at $100^{\circ} \mathrm{C}$ for $6 \mathrm{~h}$ ( $3 \mathrm{~h}$ each time) and filtered through four sheets of gauze. The filtrates were combined, centrifuged, and concentrated to about $200 \mathrm{~mL}$ with rotary evaporators. To precipitate the crude polysaccharides, 5-fold volume of $95 \%$ ethanol was added at $4^{\circ} \mathrm{C}$ overnight. The resulting precipitate was collected by centrifugation, washed with pure ethanol $(400 \mathrm{~mL})$ repeatedly, and dried by lyophilization. $50 \mathrm{~g}$ dry precipitate was obtained, reconstituted in $1000 \mathrm{~mL}$ pure water, and treated with Sevag reagent ( $n$-butanol/chloroform, v/v $=1: 4,250 \mathrm{~mL}$ ) to remove proteins. After precipitation by ethanol and lyophilization, the deproteined polysaccharide fraction (43 g) was obtained.

2.3. Chromatography on DEAE-52 Cellulose. A total of $300 \mathrm{mg}$ crude polysaccharides was dissolved, filtered through
$0.45 \mu \mathrm{m}$ filters, and applied to a DEAE-52 cellulose chromatography column $(26 \mathrm{~mm} \times 60 \mathrm{~cm})$, followed by successive elution with pure water, $0.1,0.2$, and $0.5 \mathrm{M} \mathrm{NaCl}$ solutions at a flow rate of $1 \mathrm{~mL} / \mathrm{min}$. The eluate was collected automatically (5.0 mL/tube) and monitored by the phenol-sulphuric acid method. Four different fractions were collected and concentrated, then dialyzed (MW cut off $2.0 \mathrm{kDa}$ ), and lyophilized.

2.4. Determination of Contents of Carbohydrate, Uronic Acid, and Protein. The total carbohydrate content of the samples was carried out by the phenol-sulphuric acid method using the standard curve of D-glucose $[16,17]$. Uronic acid content of the fractions was measured by sulfamate/mhydroxydiphenyl assay using glucuronic acid as standard [18]. The protein content of the samples was quantified using Bradford Protein Quantification Kit.

\subsection{Immunomodulatory Activity Assay}

2.5.1. Cell Culture. The mouse macrophage cell line, RAW 264.7 cell, was purchased from Type Culture Collection of the Chinese Academy of Sciences, Shanghai, China. The cells were cultured in DMEM medium containing 10\% fetal bovine serum and $1 \%$ penicillin/streptomycin in a humidified incubator of $5 \% \mathrm{CO}_{2}$ at $37^{\circ} \mathrm{C}$.

2.5.2. Cell Viability Assay. An MTT cell proliferation assay was used to evaluate the cytotoxicity of the red ginseng polysaccharide fractions on RAW 264.7 cells [19]. Briefly, RAW 264.7 cells $\left(1.0 \times 10^{4}\right.$ cells/well $)$ were seeded into a 96-well plate (Corning, NY, USA) and incubated for $24 \mathrm{~h}$. The cells were then treated with red ginseng polysaccharide fractions at series $(1,10,50,100$, and $1000 \mu \mathrm{g} / \mathrm{mL})$ concentrations. After $24 \mathrm{~h}$ stimulation, MTT was added to each well to a final concentration of $0.5 \mathrm{mg} / \mathrm{ml}$. The plates were further incubated for $4 \mathrm{~h}$, and then the produced formazan crystals were dissolved in DMSO. The absorbance at $570 \mathrm{~nm}$ was measured in a Thermo Scientific Varioskan Flash. The absorbance was translated into cell viability for comparison: cell viability $=A$ (sample $) / A($ control $) \times 100 \%$. The percentage of untreated cell viability was calculated as $100 \%$.

2.5.3. Measurement of NO Production. RAW 264.7 cells (1.0 $\times 10^{4}$ cells/well) were seeded into a 96-well plate (Corning, NY, USA) and incubated for $24 \mathrm{~h}$. Red ginseng polysaccharide fractions $(1,10,100$, and $1000 \mu \mathrm{g} / \mathrm{mL})$ or LPS $(5 \mu \mathrm{g} / \mathrm{mL})$ were added to the corresponding wells and cultured for $24 \mathrm{~h}$. The medium was collected and centrifuged. Next, the supernatant was determined using the kits for the analysis of NO (Griess) according to the manufacturer's instructions.

2.5.4. Measurement of Phagocytic Activity. The phagocytic ability of macrophages was measured by neutral red uptake [20]. Briefly, RAW 264.7 cells $\left(1.0 \times 10^{4}\right.$ cells/well $)$ were incubated with red ginseng polysaccharide fractions $(1,10$, 100 , and $1000 \mu \mathrm{g} / \mathrm{mL})$ or LPS $(5 \mu \mathrm{g} / \mathrm{mL})$ for $24 \mathrm{~h}$, and then $100 \mu \mathrm{L}$ of aseptic neutral red solution $(0.075 \%)$ was added to each well and incubated for another $0.5 \mathrm{~h}$. After being washed 
with PBS, the cells were lysed by adding $150 \mu \mathrm{L}$ cell lysis buffer (anhydrous ethanol: acetic acid $=1: 1, \mathrm{v} / \mathrm{v}$ ). The absorbance was measured at $540 \mathrm{~nm}$ using Thermo Scientific Varioskan Flash. The absorbance represented the phagocytic ability of the macrophages.

2.5.5. Measurement of TNF- $\alpha$ Production. Based on the NO production and phagocytic activity assay, red ginseng polysaccharide fractions RGP1 and RGP2 were chosen for measurement of TNF- $\alpha$ production. In this assay, RAW 264.7 cells were prepared as in the NO assay preparation section. The cells were then incubated with RGP1 and RGP2 with different concentrations $(1,50,100,250,500$, and $1000 \mu \mathrm{g} / \mathrm{mL})$ or LPS $(1 \mu \mathrm{g} / \mathrm{mL})$ for $24 \mathrm{~h}$. Supernatants were harvested, and TNF- $\alpha$ production was determined using a mouse TNF$\alpha$ enzyme linked immunosorbent assay according to the manufacturer's instructions.

2.6. Gel Permeation Chromatography on Sephadex G-100. Red ginseng polysaccharide fractions RGP1 and RGP2 were chosen for further purification. Each sample $(10 \mathrm{mg})$ was dissolved, filtered through $0.45 \mu \mathrm{m}$ filters, loaded onto a Sephadex G-100 chromatography column $(26 \mathrm{~mm} \times 80 \mathrm{~cm})$, and then eluted with pure water at a flow rate of $0.5 \mathrm{~mL} / \mathrm{min}$. The eluate was collected automatically and monitored by the phenol-sulphuric acid method, then concentrated, and lyophilized to obtain RGP2-1.

\subsection{Preliminary Characterization of RGP1 and RGP2-1}

2.7.1. Homogeneity and Molecular Weight Analysis. The homogeneity and molecular weight of RGP2-1 were determined by HPLC on an Agilent 1200 system equipped with a TSK-GEL G4000PWXL column and an evaporative light scattering detector (ELSD). The sample $(2 \mathrm{mg})$ was dissolved in the pure water $(0.5 \mathrm{~mL})$ and filtered through $0.45 \mu \mathrm{m}$ filters, and $40 \mu \mathrm{L}$ of supernatant was injected in a run with pure water as the mobile phase at a flow rate of $0.6 \mathrm{~mL} / \mathrm{min}$. The molecular mass was estimated with reference to a calibration curve made from a set of Dextran T-series standards of known molecular mass (Mw 100, 70, 50, 20, and $10 \mathrm{kDa}$ ) [21]. Calibration curve of $\log \mathrm{Mw}$ (molecular weight) of standard dextrans against their retention time $\left(R_{t}\right)$ was acquired $\left(\log \mathrm{Mw}=-0.1981 R_{t}+7.820, R^{2}=0.9978\right)$.

2.7.2. Analysis of Monosaccharide Composition. GC-MS was used for qualitative and quantitative analyses of the monosaccharide composition [22]. Each sample (5 $\mathrm{mg}$ ) was dissolved in $2 \mathrm{M}$ trifluoroacetic acid (TFA, $4 \mathrm{~mL}$ ) and hydrolyzed at $100^{\circ} \mathrm{C}$ for $6 \mathrm{~h}$, then removing superfluous TFA via repeatedly coconcentrating with methanol. Acetylation was carried out with $10 \mathrm{mg}$ hydroxylamine hydrochloride and $0.6 \mathrm{~mL}$ pyridine for $30 \mathrm{~min}$ at $90^{\circ} \mathrm{C}$. Acetic anhydride $(1 \mathrm{~mL})$ was then added with continuous heating, and the alditol acetate derivatives were analyzed by a Agilent 7890A-5975C GCMS (Agilent, USA) equipped with a total ionization detector (TIC) and a DB-5MS capillary column $(30 \mathrm{~m} \times 0.25 \mathrm{~mm}$ $\times 0.25 \mu \mathrm{m}$, Agilent). The flow rate of carrier gas $(\mathrm{He})$ was

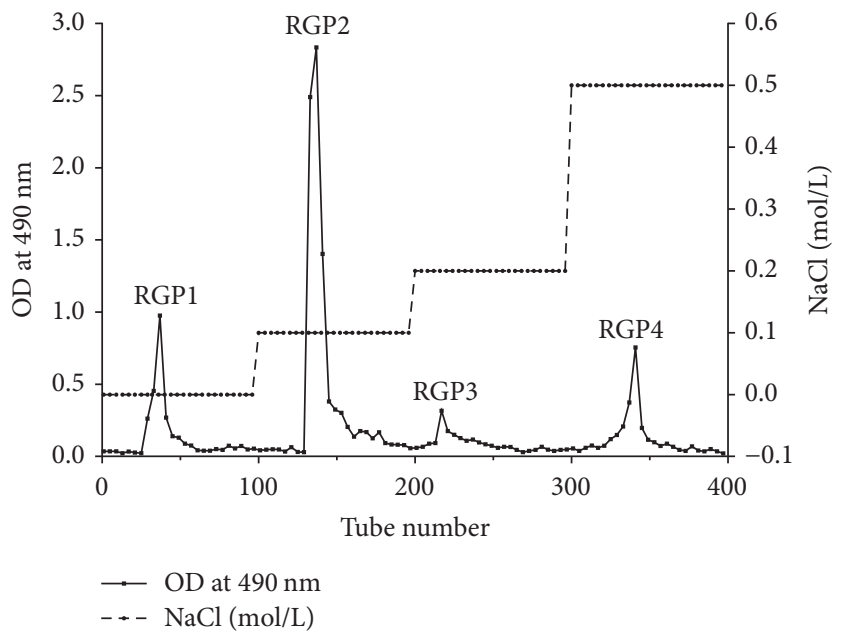

FIGURE 1: Stepwise elution profile of red ginseng crude polysaccharides on DEAE-52 cellulose anion-exchange column.

set at $1 \mathrm{~mL} / \mathrm{min}$. The temperature of the column oven was programmed as follows: (1) $100^{\circ} \mathrm{C}$ for $1 \mathrm{~min}$; (2) increasing to $190^{\circ} \mathrm{C}$ at $20^{\circ} \mathrm{C} / \mathrm{min}$; and (3) increasing to $300^{\circ} \mathrm{C}$ at $10^{\circ} \mathrm{C} / \mathrm{min}$.

2.7.3. FT-IR Spectrum Analysis. Each sample $(1 \mathrm{mg})$ was ground with $\mathrm{KBr}(100 \mathrm{mg})$ powder and pressed into a sheet. The spectra were recorded on a Thermo Nicolet 6700 FT-IR spectrophotometer in the range of $400-4000 \mathrm{~cm}^{-1}$.

2.8. Statistical Analysis. The MTT assay, nitric oxide production assay, and phagocytosis analysis were performed no fewer than three times each. Mean data values are presented with their deviation (mean $\pm \mathrm{SD}$ ). Analysis of variance (ANOVA) was followed by $t$-test for pairwise comparison. Statistical significance was defined as $p<0.05$ for all tests. The analyses were carried out using SPSS version 22.0 (SPSS Inc., Chicago, IL, USA).

\section{Results and Discussion}

3.1. Fractionation by DEAE-52 Cellulose Chromatography and Chemical Characterization of Fractions. Four different fractions were obtained by using anion-exchange chromatography on DEAE-52 cellulose column as shown in Figure 1: RGP1 (eluted with pure water), RGP2 (eluted with $0.1 \mathrm{M} \mathrm{NaCl}$ ), RGP3 (eluted with $0.2 \mathrm{M} \mathrm{NaCl}$ ), and RGP4 (eluted with $0.5 \mathrm{M}$ $\mathrm{NaCl}$ ) with yields of $16.7,49.3,12.0$, and $8.0 \%$, respectively. The chemical parameters of four fractions were shown in Table 1 . All of four fractions had quite high carbohydrate content. The uronic acid of RGP1, RGP2, RGP3, and RGP4 were 4.2, $13.6,17.8$, and $8.4 \%$, respectively. Each fraction contained no protein.

\subsection{Effects on Immune Response in RAW 264.7 Cells}

3.2.1. Effects of RGP1, RGP2, RGP3, and RGP4 on RAW 264.7 Cell Viability. Macrophage cell is one kind of phagocyte that plays key roles in the innate immune responses and host 


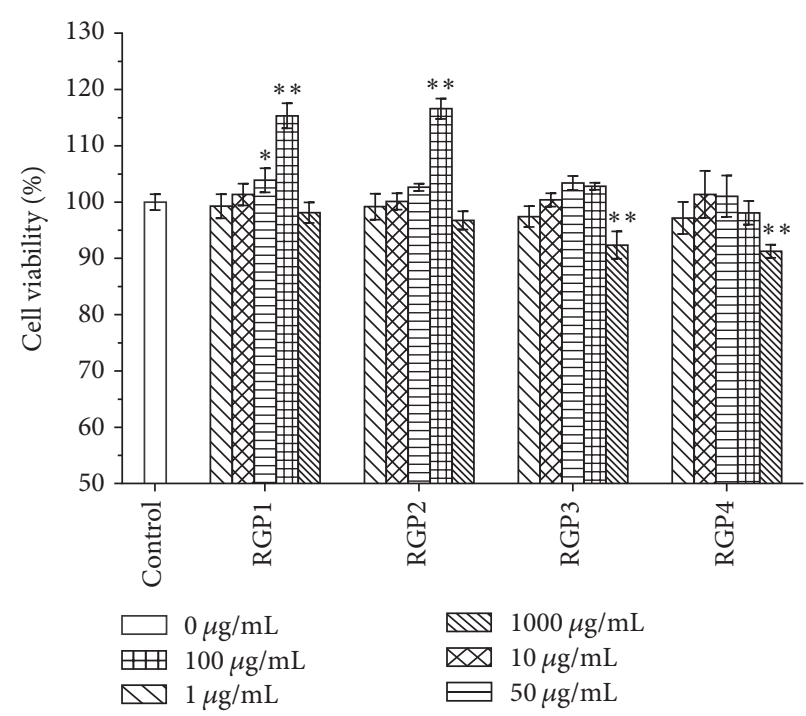

(a)

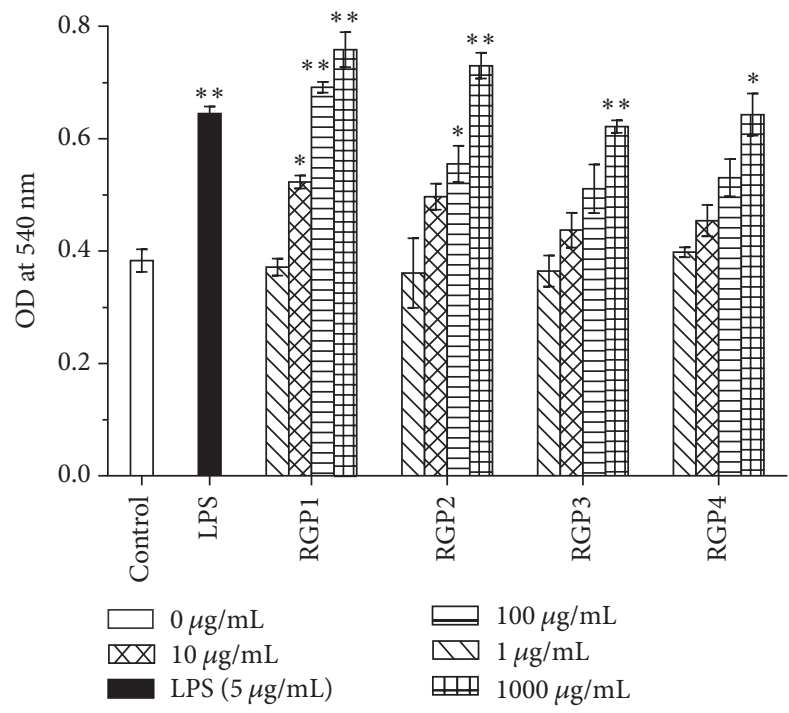

(c)

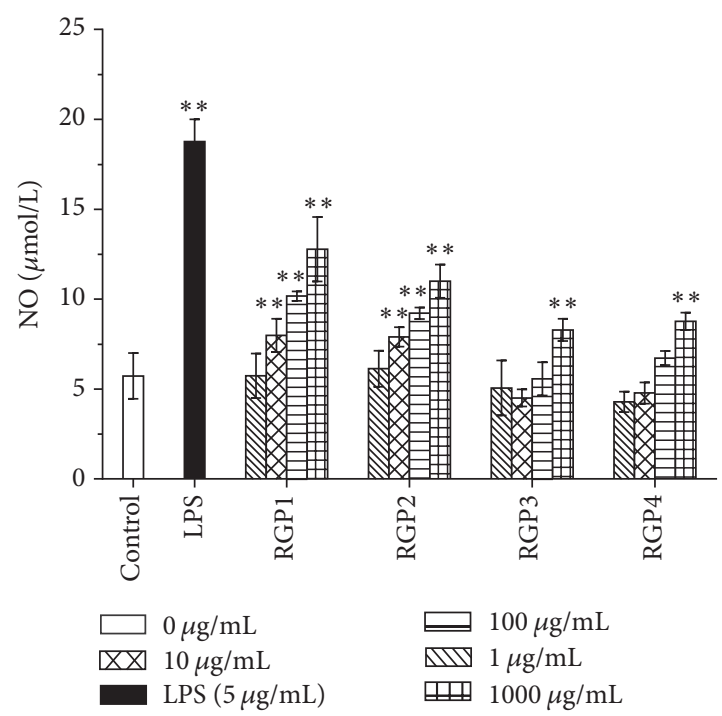

(b)

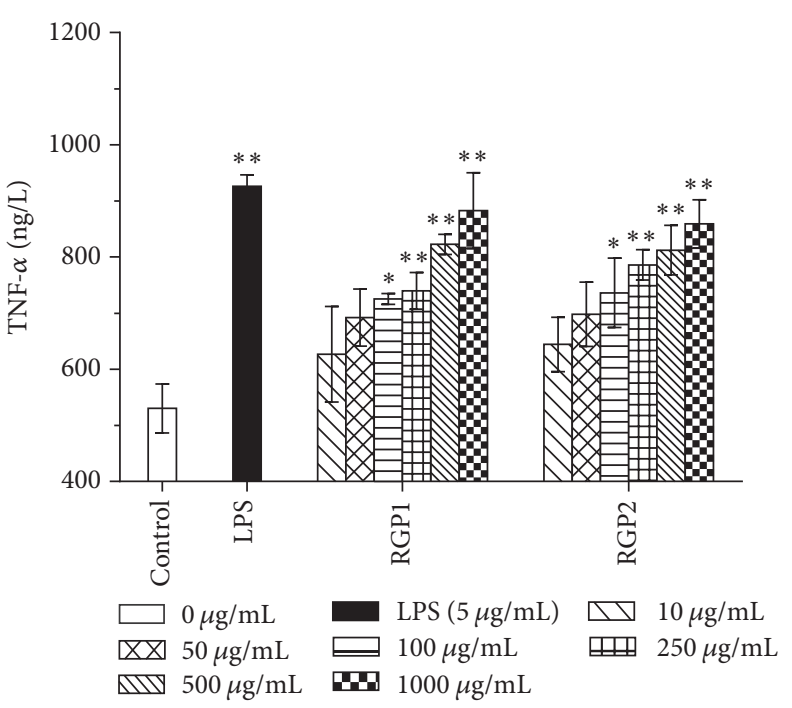

(d)

FIGURE 2: Immunomodulatory activities of red ginseng polysaccharide fractions in RAW 264.7 cells. (a) Effects of RGP1, RGP2, RGP3, and RGP4 on RAW 264.7 cell viability. (b) Effects of RGP1, RGP2, RGP3, and RGP4 on NO production. (c) Effects of RGP1, RGP2, RGP3, and RGP4 on phagocytic activity. (d) Effects of RGP1 and RGP2 on TNF- $\alpha$ production. Each value was expressed as mean \pm SD $(n=3)$. indicates $p<0.05 ; * *$ indicates $p<0.01$ compared with the control group.

defense system. The activation of macrophages is a key event for initiating and propagating defensive reactions against pathogen infection [23]. The effects of RGP1, RGP2, RGP3, and RGP4 with concentrations from 1 to $1000 \mu \mathrm{g} / \mathrm{mL}$ on macrophages metabolic activity using the MTT method are shown in Figure 2(a). Compared with control group, the cell viability of RAW 264.7 cells treated with RGP1 and RGP2 at a concentration of $100 \mu \mathrm{g} / \mathrm{mL}$ was significantly increased $(115.3 \% \pm 2.2$ and $116.6 \% \pm 1.8$, resp., $p<0.05)$. Although RGP3 and RGP4 showed cytotoxic effect at the maximum concentration tested $(1000 \mu \mathrm{g} / \mathrm{mL})$, the cell viability values still reach to over $90 \%(92.4 \% \pm 2.4$ and $91.3 \% \pm 1.2$, resp., $p<0.05)$. Generally, cell viability of more than $90 \%$ indicated that the compounds at the concentrations were considered nontoxic to the cells [24]. Therefore, it could be concluded that none of the polysaccharide fractions had cytotoxic effects on RAW 264.7 cells under the concentration of $1000 \mu \mathrm{g} / \mathrm{mL}$.

\subsubsection{Effects of RGP1, RGP2, RGP3, and RGP4 on NO Produc-} tion. NO is a gaseous molecule synthesized from $\mathrm{L}$-arginine by nitric oxide synthase (NOS) and is believed to be a major mediator of macrophages and essential for the resistance of immune system to pathogens invasion, an inducer or suppressor of apoptosis, and an immunoregulator [25]. NO has been identified as a quantitative index of macrophage activation [26]. As shown in Figure 2(b), RGP1, RGP2, RGP3, and RGP4 could significantly enhance NO production $(\geq 10 \mu \mathrm{g} / \mathrm{mL}, \geq 10 \mu \mathrm{g} / \mathrm{mL}, 1000 \mu \mathrm{g} / \mathrm{mL}, 1000 \mu \mathrm{g} / \mathrm{mL}$, resp., 
TABLE 1: The chemical compositions of fractions.

\begin{tabular}{lccc}
\hline Sample & Total carbohydrate (\%) & Uronic acid (\%) & Protein (\%) \\
\hline RGP1 & $92.0 \pm 1.3$ & $4.2 \pm 0.3$ & ND \\
RGP2 & $73.1 \pm 1.5$ & $13.6 \pm 0.4$ & ND \\
RGP3 & $80.0 \pm 0.5$ & $17.8 \pm 0.6$ & ND \\
RGP4 & $72.4 \pm 0.3$ & $8.4 \pm 0.6$ & ND \\
\hline
\end{tabular}

$\mathrm{ND}=$ not detected.

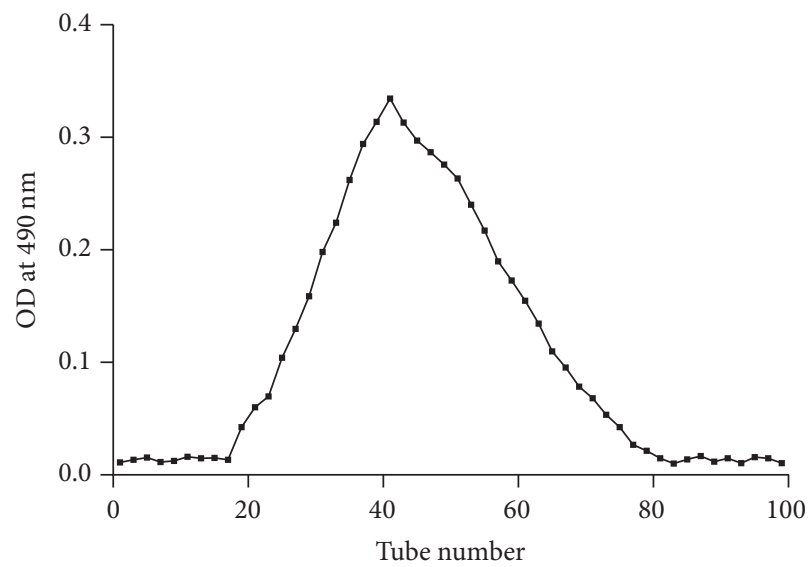

(a)

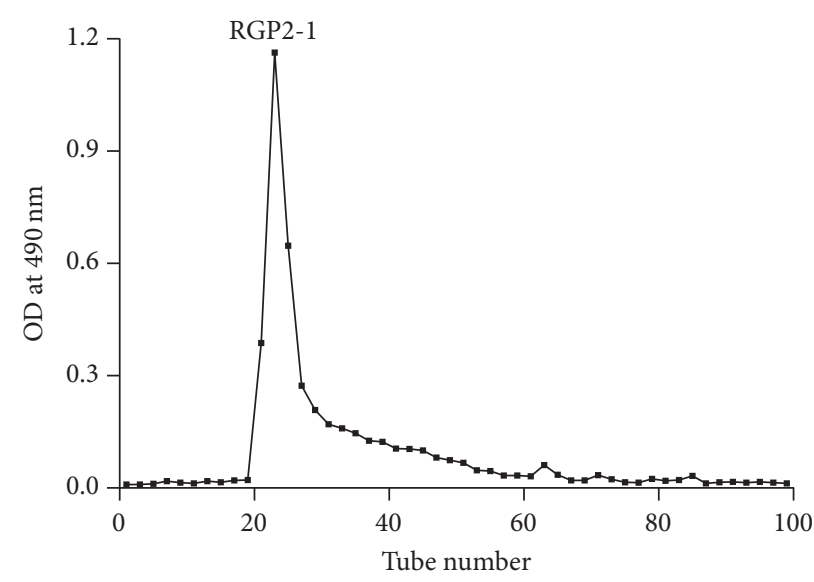

(b)

Figure 3: Sephadex G-100 profiles of (a) RGP1 and (b) RGP2.

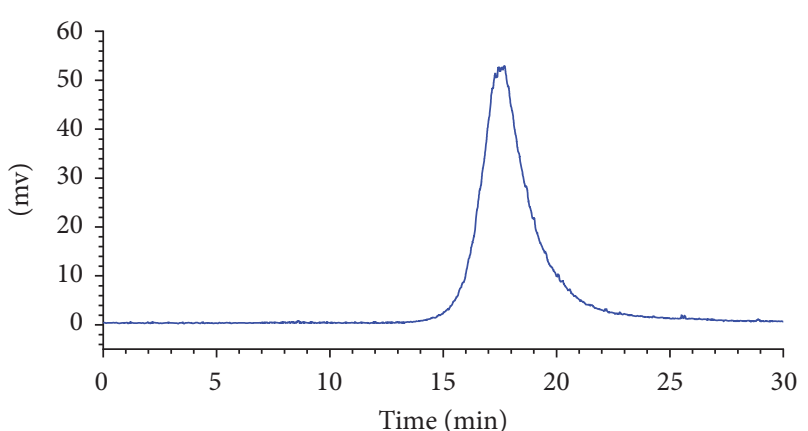

FIGURE 4: HPGPC chromatogram of RGP2-1 on TSK-GEL G4000PWXL column.

$p<0.01$ ), compared with control group. NO production induced by RGP1 and RGP2 was found to have a better effect on the activation of macrophages than RGP3 and RGP4.

\subsubsection{Effects of RGP1, RGP2, RGP3, and RGP4 on Phagocytic} Activity. Increased phagocytic activity is one of the most distinguishable features of macrophage activation. Thus, the phagocytic activity of polysaccharide-activated macrophages was studied by the uptake of neutral red. As shown in Figure 2(c), RGP1, RGP2, RGP3, and RGP4 could significantly stimulate the phagocytic activity of RAW 264.7 cells compared with control group $(\geq 10 \mu \mathrm{g} / \mathrm{mL}, \geq 100 \mu \mathrm{g} / \mathrm{mL}$, $1000 \mu \mathrm{g} / \mathrm{mL}$, and $1000 \mu \mathrm{g} / \mathrm{mL}$, resp., $p<0.05)$. At concentrations of 100 and $1000 \mu \mathrm{g} / \mathrm{mL}, \mathrm{RGP} 1$ and RGP2 exhibited a stronger effect on pinocytic activity of macrophages than RGP3 and RGP4. Since the current results indicated that RGP1 and RGP2 had a better effect on promoting the proliferation, NO production and neutral red phagocytosis of RAW 264.7 macrophage cells in vitro than RGP3 and RGP4, RGP1, and RGP2 were chosen for the assays of TNF- $\alpha$ production, further purification, and physicochemical characterization.

3.2.4. Effects of RGP1 and RGP2 on TNF- $\alpha$ Production. As a significant part of host defense system, activated macrophages can produce various mediators and cytokines, which play potential roles in cellular and humoral immune responses and defense against cancer cells. TNF- $\alpha$ plays a crucial role in immune-regulation and can also induce tumor cell apoptosis [27]. The effects of RGP-1 and RGP-2 on the TNF- $\alpha$ production are shown in Figure 2(d). Compared with control group, the level of TNF- $\alpha$ in RAW 264.7 cells was increased significantly in RGP1 and RGP2 groups $(p<$ $0.05)$. At a concentration range of $100-1000 \mu \mathrm{g} / \mathrm{mL}$, a dosedependent increasing the secretion of TNF- $\alpha$ was observed in macrophages treated with RGP1 and RGP2.

3.3. Fractionation by Sephadex G-100 Chromatography. RGP1 and RGP2 were further purified by a Sephadex G-100 column. As shown in Figure 3, RGP1 give a wide distribution, almost from the void volume to the total volume, which indicated that RGP1 had a relatively low degree of homogeneity and it was very difficult to further be fractionated by gel permeation chromatography. However, RGP2 showed a relatively narrow distribution and yield one main fraction named RGP2-1. 


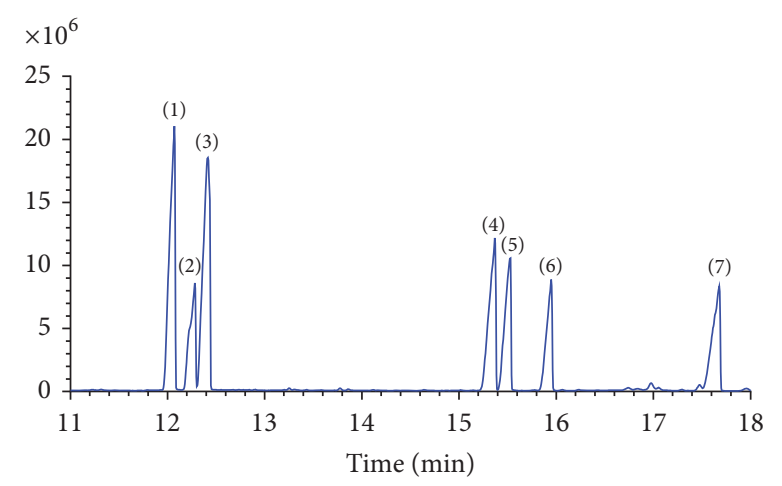

(a)

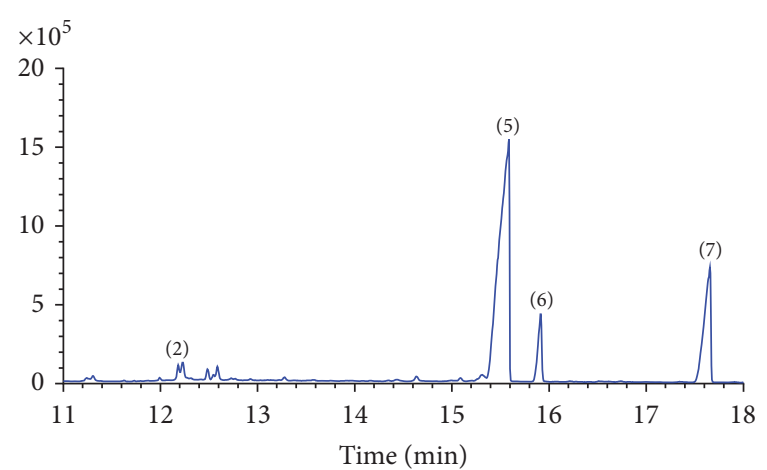

(b)

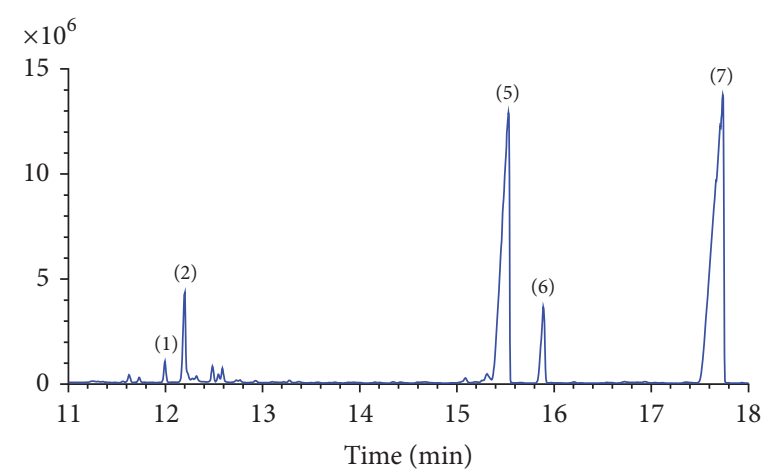

(c)

FIGURE 5: GC-MS analysis of monosaccharide composition of derivatives of (a) six standards, (b) RGP1 and (c) RGP2-1. (1) Rhamnose; (2) arabinose; (3) xylose; (4) mannose; (5) glucose; (6) galactose; (7) inositol.

3.4. Preliminary Characterization of RGP1 and RGP2-1. Homogeneity and molecular weight of RGP2-1 were estimated by HPGPC. As shown in Figure 4, RGP2-1 exhibited a single and symmetrical peak in HPGPC. Based on the calibration curve of Dextran standards, the average molecular weight of RGP2-1 was estimated to be $2.16 \times 10^{4} \mathrm{Da}$. The monosaccharide composition of RGP1 and RGP2-1 was determined by GC-MS analysis. As shown in Figure 5, RGP1 was found to consist of arabinose, glucose, and galactose with a relative molecular ratio of $0.02: 0.88: 0.10$. RGP2-1 consisted of rhamnose, arabinose, glucose, and galactose with a relative molecular ratio of $0.02: 0.10: 0.77: 0.11$. Both RGP1 and RGP2-1 were mainly composed of glucose, which indicated that RGP1 and RGP2-1 were two neutral fractions and their backbones were composed of glucose. FT-IR spectra of RGP1 and RGP2-1 appear in Figure 6. The characteristic broad peaks of RGP1 and RGP2-1 at $3428.02 / 3403.40 \mathrm{~cm}^{-1}$ correspond to the hydroxyl stretching vibration. The absorption peaks RGP1 and RGP2-1 at 2927.55/2928.98 $\mathrm{cm}^{-1}$ correspond to the C-H stretching vibration. The absorption of RGP1 and RGP2-1 at $1154.83 / 1152.59 \mathrm{~cm}^{-1}, 1080.20 / 1079.00 \mathrm{~cm}^{-1}$, and $1023.75 / 1023.53 \mathrm{~cm}^{-1}$ indicated the bending vibrational modes of $\mathrm{C}-\mathrm{O}$ stretching in the pyranose form. In addition, the peak at $859.08 \mathrm{~cm}^{-1}$ resulted from the presence of $\alpha$ glycosidic bounds $[28,29]$.
It has been reported that ginseng polysaccharides are categorized into neutral and acidic polysaccharides. The neutral polysaccharides mainly contain different ratios of neutral sugar residues. The acidic polysaccharides were composed of different amounts of galacturonic acid and neutral sugars and have been evidenced to have most of the biological effect with ginsenosides $[30,31]$. In present study, we found that RGP1 and RGP2-1 are two neutral fractions, and the RGP2-1 was different from the already reported neutral polysaccharides isolated from nonsteamed $P$. ginseng root [30], which suggested that RGP2-1 could be considered as a novel homogeneous polysaccharide. Furthermore, the current results showed that these two neutral polysaccharide fractions made a great contribution to the immunomodulatory activities of red ginseng polysaccharides, which is consistent with the finding reported in the literature that the neutral $P$. ginseng polysaccharides were more active as mitogens than the acidic polysaccharides [32]. Polysaccharides composed of glucan have been proved to stimulate the immune system [33]. The immunomodulatory activity of RGP1 and RGP2 might be due to its high contents of glucose. However, most of the research on red ginseng polysaccharides has centered on its acidic polysaccharides, and there is relatively limited research that explores neutral polysaccharides. Our results suggest that the neutral polysaccharides may be more potent stimulators than 


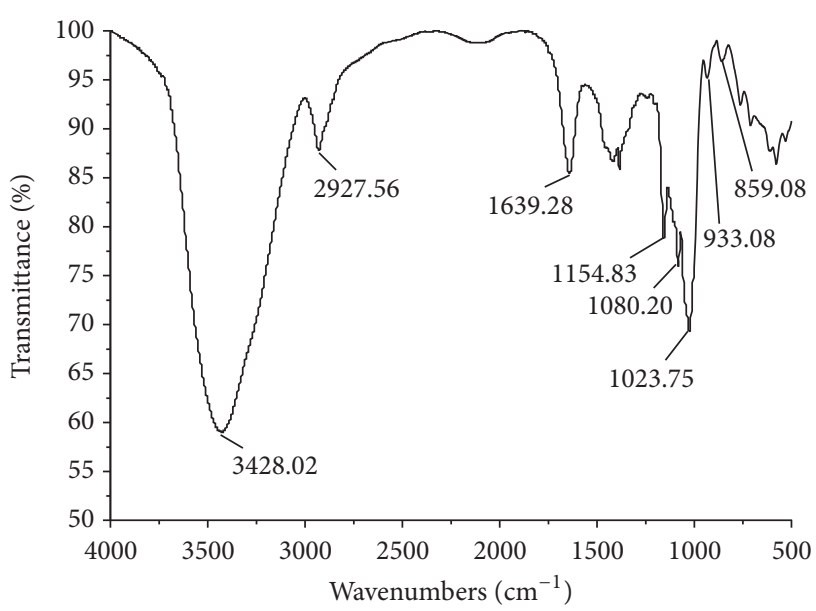

(a)

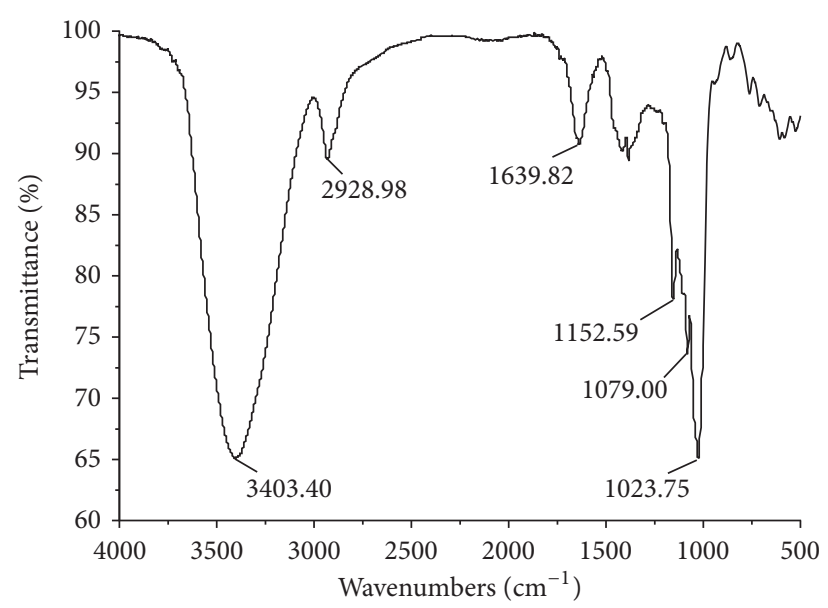

(b)

FIGURE 6: Infrared spectra of (a) RGP1 and (b) RGP2-1.

the acidic polysaccharides of red ginseng and more attention should be paid to the neutral polysaccharides.

\section{Conclusions}

In the present study, four polysaccharide fractions were obtained from red ginseng. RGP1 and RGP2 were shown to have stronger immunomodulatory activities compared to other fractions. RGP2 can be further fractionate into a homogeneous fraction RGP2-1 with average molecular weight of $2.16 \times 10^{4} \mathrm{Da}$. Monosaccharides analysis revealed that RGP1 and RGP2-1 were neutral polysaccharides. RGP1 was found to consist of arabinose, glucose, and galactose with a molecular ratio of $0.02: 0.88: 0.10$. RGP2-1 consisted of rhamnose, arabinose, glucose, and galactose with a molecular ratio of 0.02:0.10:0.77:0.11. These findings imply that RGP1 and RGP2 may be used as candidates for developing immunomodulating agents in food and pharmaceutical industries. Further studies on their precise chemical structures and in vivo biological functions are currently in progress.

\section{Conflicts of Interest}

The authors declare that there are no conflicts of interest regarding the publication of this paper.

\section{Acknowledgments}

This work was supported by the National Natural Science Foundation of China (no. 81473318). The authors acknowledge SJTULAB group for their research support.

\section{References}

[1] J. D. Park, D. K. Rhee, and Y. H. Lee, "Biological activities and chemistry of saponins from Panax ginseng C. A. Meyer," Phytochemistry Reviews, vol. 4, no. 2-3, pp. 159-175, 2005.
[2] S. Y. Lee, Y. K. Kim, N. I. Park, C. S. Kim, C. Y. Lee, and S. U. Park, "Chemical constituents and biological activities of the berry of Panax ginseng," Journal of Medicinal Plant Research, vol. 4, no. 5, pp. 349-53, 2010.

[3] S. M. Lee, S. C. Kim, J. Oh, J. H. Kim, and M. Na, "20(R)Ginsenoside Rf: a new ginsenoside from red ginseng extract," Phytochemistry Letters, vol. 6, no. 4, pp. 620-624, 2013.

[4] M. C. Kho, Y. J. Lee, J. H. Park et al., "Fermented red ginseng potentiates improvement of metabolic dysfunction in metabolic syndrome rat models," Nutrients, vol. 8, no. 6, article 369, 2016.

[5] H. Y. Kim, K. S. Kang, N. Yamabe, and T. Yokozawa, "Comparison of the effects of Korean Ginseng and heat-processed Korean Ginseng on diabetic oxidative stress," The American Journal of Chinese Medicine, vol. 36, no. 5, pp. 989-1004, 2008.

[6] W. Y. Kim, J. M. Kim, S. B. Han et al., "Steaming of ginseng at high temperature enhances biological activity," Journal of Natural Products, vol. 63, no. 12, pp. 1702-1704, 2000.

[7] Y. Jin, Y.-J. Kim, J.-N. Jeon et al., "Effect of white, red and black ginseng on physicochemical properties and ginsenosides," Plant Foods for Human Nutrition, vol. 70, no. 2, pp. 141-145, 2015.

[8] P. Y. K. Yue, D. Y. L. Wong, P. K. Wu et al., "The angiosuppressive effects of 20(R)-ginsenoside Rg3," Biochemical Pharmacology, vol. 72, no. 4, pp. 437-445, 2006.

[9] Y.-W. Shin, E.-A. Bae, and D.-H. Kim, "Inhibitory effect of ginsenoside $\operatorname{Rg} 5$ and its metabolite ginsenoside $\mathrm{Rh} 3$ in an oxazolone-induced mouse chronic dermatitis model," Archives of Pharmacal Research, vol. 29, no. 8, pp. 685-690, 2006.

[10] Y.-M. Shin, H.-J. Jung, W.-Y. Choi, and C.-J. Lim, "Antioxidative, anti-inflammatory, and matrix metalloproteinase inhibitory activities of 20(S)-ginsenoside Rg3 in cultured mammalian cell lines," Molecular Biology Reports, vol. 40, no. 1, pp. 269-279, 2013.

[11] K.-T. Choi, "Botanical characteristics, pharmacological effects and medicinal components of Korean Panax ginseng C. A. Meyer," Acta Pharmacologica Sinica, vol. 29, no. 9, pp. 1109-1118, 2008.

[12] M. J. Shin, Y. S. Kim, Y. S. Kwak, Y. B. Song, Y. S. Kim, and J. D. Park, "Enhancement of antitumor effects of paclitaxel (taxol) in combination with red ginseng acidic polysaccharide (RGAP)," Planta Medica, vol. 70, no. 11, pp. 1033-1038, 2004. 
[13] K. M. Park, Y. S. Kim, T. C. Jeong et al., "Nitric oxide is involved in the immunomodulating activities of acidic polysaccharide from Panax ginseng," Planta Medica, vol. 67, no. 2, pp. 122-126, 2001.

[14] S. E. Byeon, J. Lee, J. H. Kim et al., "Molecular mechanism of macrophage activation by red ginseng acidic polysaccharide from Korean red ginseng," Mediators of Inflammation, vol. 2012, Article ID 732860, 7 pages, 2012.

[15] Y.-S. Kwak, J.-S. Kyung, J. S. Kim, J. Y. Cho, and M.-H. Rhee, "Anti-hyperlipidemic effects of red ginseng acidic polysaccharide from Korean red ginseng," Biological \& Pharmaceutical Bulletin, vol. 33, no. 3, pp. 468-472, 2010.

[16] R. Chen, F. Meng, Z. Liu, R. Chen, and M. Zhang, "Antitumor activities of different fractions of polysaccharide purified from Ornithogalum caudatum Ait," Carbohydrate Polymers, vol. 80, no. 3, pp. 845-851, 2010.

[17] T. Masuko, A. Minami, N. Iwasaki, T. Majima, S.-I. Nishimura, and Y. C. Lee, "Carbohydrate analysis by a phenol-sulfuric acid method in microplate format," Analytical Biochemistry, vol. 339, no. 1, pp. 69-72, 2005.

[18] T. M. C. C. Filisetti-Cozzi and N. C. Carpita, "Measurement of uronic acids without interference from neutral sugars," Analytical Biochemistry, vol. 197, no. 1, pp. 157-162, 1991.

[19] T. Mosmann, "Rapid colorimetric assay for cellular growth and survival: application to proliferation and cytotoxicity assays," Journal of Immunological Methods, vol. 65, no. 1-2, pp. 55-63, 1983.

[20] M. Wang, C. Jiang, L. Ma et al., "Preparation, preliminary characterization and immunostimulatory activity of polysaccharide fractions from the peduncles of Hovenia dulcis," Food Chemistry, vol. 138, no. 1, pp. 41-47, 2013.

[21] M. Lin, B. Xia, M. Yang, S. Gao, Y. Huo, and G. Lou, "Characterization and antitumor activities of a polysaccharide from the rhizoma of Menispermum dauricum," International Journal of Biological Macromolecules, vol. 53, pp. 72-76, 2013.

[22] N. Li, C. Yan, D. Hua, and D. Zhang, "Isolation, purification, and structural characterization of a novel polysaccharide from Ganoderma capense," International Journal of Biological Macromolecules, vol. 57, pp. 285-290, 2013.

[23] I. A. Schepetkin, G. Xie, L. N. Kirpotina, R. A. Klein, M. A. Jutila, and M. T. Quinn, "Macrophage immunomodulatory activity of polysaccharides isolated from Opuntia polyacantha," International Immunopharmacology, vol. 8, no. 10, pp. 14551466, 2008.

[24] B. Zhang, X.-M. Zhu, J.-N. Hu et al., "Absorption mechanism of ginsenoside compound $\mathrm{K}$ and its butyl and octyl ester prodrugs in caco-2 cells," Journal of Agricultural and Food Chemistry, vol. 60, no. 41, pp. 10278-10284, 2012.

[25] C. Bogdan, M. Röllinghoff, and A. Diefenbach, "The role of nitric oxide in innate immunity," Immunological Reviews, vol. 173, pp. 17-26, 2000.

[26] I. A. Schepetkin, C. L. Faulkner, L. K. Nelson-Overton, J. A. Wiley, and M. T. Quinn, "Macrophage immunomodulatory activity of polysaccharides isolated from Juniperus scopolorum," International Immunopharmacology, vol. 5, no. 13-14, pp. 17831799, 2005.

[27] S. Zhang, S. Nie, D. Huang, J. Huang, Y. Feng, and M. Xie, "A polysaccharide from Ganoderma atrum inhibits tumor growth by induction of apoptosis and activation of immune response in CT26-bearing mice," Journal of Agricultural and Food Chemistry, vol. 62, no. 38, pp. 9296-9304, 2014.
[28] D. Rout, S. Mondal, I. Chakraborty, M. Pramanik, and S. S. Islam, "Chemical analysis of a new $(1 \rightarrow 3)-,(1 \rightarrow 6)$-branched glucan from an edible mushroom, Pleurotus florida," Carbohydrate Research, vol. 340, no. 16, pp. 2533-2539, 2005.

[29] R. Karthikeyan, T. Manivasagam, P. Anantharaman, T. Balasubramanian, and S. T. Somasundaram, "Chemopreventive effect of Padina boergesenii extracts on ferric nitrilotriacetate (Fe-NTA)induced oxidative damage in Wistar rats," Journal of Applied Phycology, vol. 23, no. 2, pp. 257-263, 2011.

[30] Y. Sun, "Structure and biological activities of the polysaccharides from the leaves, roots and fruits of Panax ginseng C. A. Meyer: an overview," Carbohydrate Polymers, vol. 85, no. 3, pp. 490-499, 2011.

[31] S. M. Lee, B.-S. Bae, H.-W. Park et al., "Characterization of Korean red ginseng (Panax ginseng Meyer): history, preparation method, and chemical composition," Journal of Ginseng Research, vol. 39, no. 4, pp. 384-391, 2015.

[32] X. Zhang, L. Yu, H. Bi et al., "Total fractionation and characterization of the water-soluble polysaccharides isolated from Panax ginseng C. A. Meyer," Carbohydrate Polymers, vol. 77, no. 3, pp. 544-552, 2009.

[33] H. Kuang, Y. Xia, B. Yang, Q. Wang, and Y. Wang, "Screening and comparison of the immunosuppressive activities of polysaccharides from the stems of Ephedra sinica Stapf," Carbohydrate Polymers, vol. 83, no. 2, pp. 787-795, 2011. 

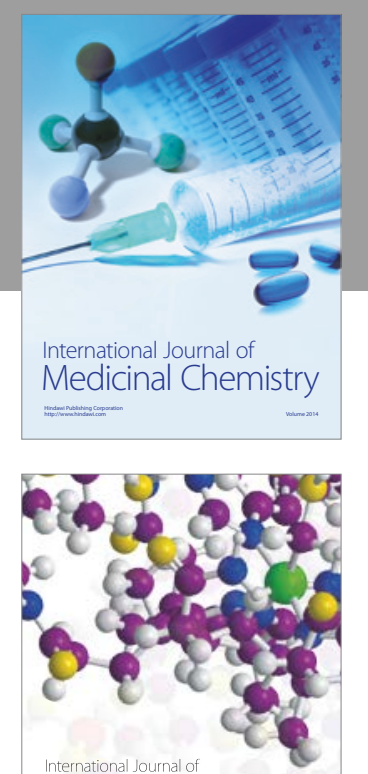

Carbohydrate Chemistry

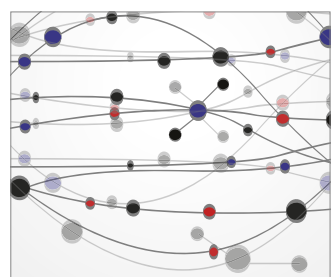

The Scientific World Journal
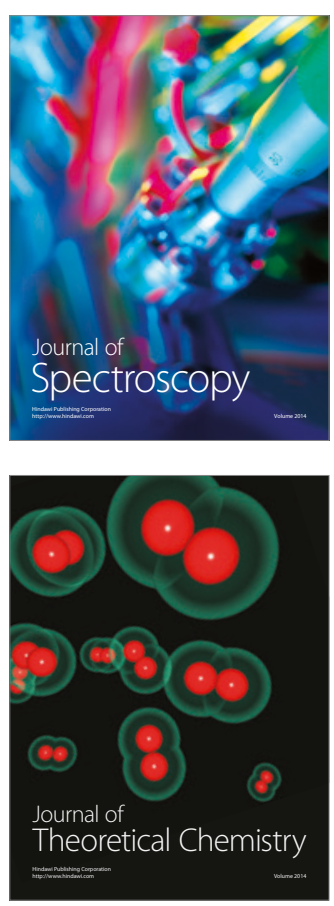
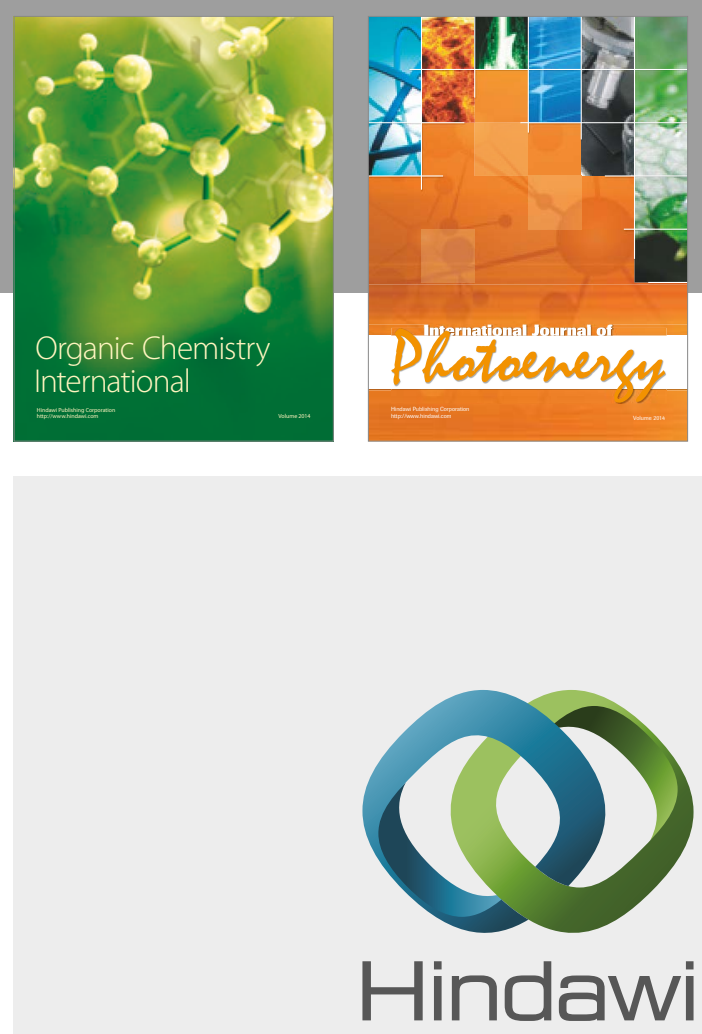

Submit your manuscripts at

https://www.hindawi.com

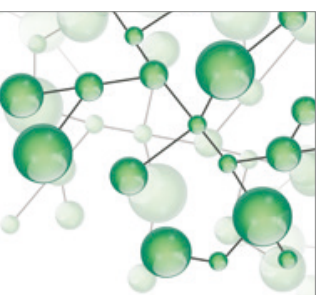

International Journal of

Inorganic Chemistry

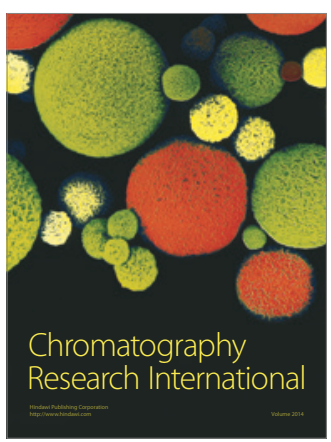

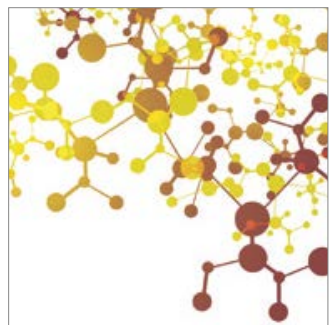

Applied Chemistry
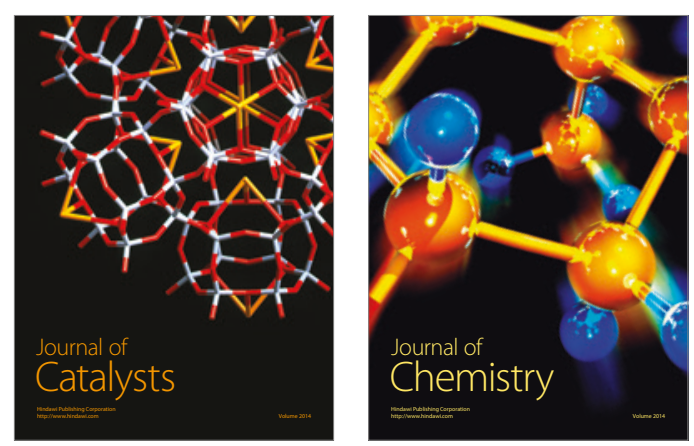
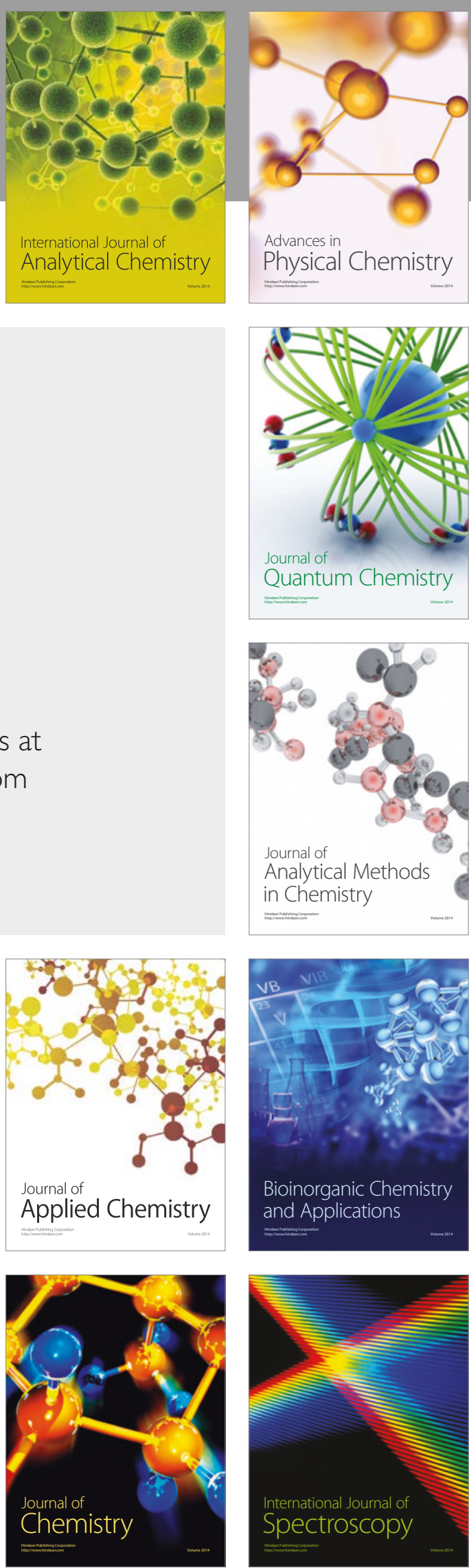